\title{
Simulation of Incremental Conductance MPPT Algorithm for PV Systems using LabVIEW
}

\author{
P Srinivas ${ }^{1}$, K Vijaya Lakshmi ${ }^{2}$, Ch Ramesh ${ }^{3}$ \\ Associate Professor, Dept. of EIE, VR Siddhartha Engineering College, Vijayawada, India ${ }^{1}$ \\ Assistant Professor, Dept. of EIE, VR Siddhartha Engineering College, Vijayawada, India ${ }^{2}$ \\ Professor, Dept. of EIE, Bapatla Engineering College, Bapatla, India ${ }^{3}$
}

\begin{abstract}
Among all types of renewable energies, solar energy has the widespread utilization. This popularity is achieved for its sustainability, cleanliness, ease of maintenance and absolute zero noise characteristics. The global economic convenience of a PV system depends on the cost and the energy conversion efficiency. It is necessary to reduce the cost and increase the efficiency to make solar energy effectively. Thus, MPPT algorithm is necessary in order to track the optimum operating point or maximum power that can be extracted from the PV array. In this paper, Incremental Conductance MPPT algorithm is implemented using LabVIEW (Laboratory Virtual Instrument Engineering Workbench) and its performance is observed.
\end{abstract}

Keywords: PV system, Incremental conductance, MPPT algorithm, LabVIEW.

\section{INTRODUCTION}

Energy is absolutely essential for our life. Recently, with the industrial development, the conventional fossil energy sources are rapidly declining and the cost of energy is rising, and a looming energy is more $\&$ more becoming an obstacle to social development. Among all types of renewable energy sources, solar energy regarded as the green energy of the new energy and becomes a promising alternative source due to its availability and low noise characteristics. The solar energy is popularly used to provide heat, light and electricity. One of the most important technologies is photovoltaic (PV) which converts the radiation directly to electricity by the photovoltaic effect. This generated voltage is used for charging batteries which is further given to $\mathrm{AC}$ or $\mathrm{DC}$ loads depending on the load used. The PV module converts the incident solar radiation into electrical power. For the better utilisation of the power generated Maximum Power Point Tracking technique is preferred. The maximum power point tracking mechanism makes use of an algorithm and an electronic circuitry. The mechanism is based on the principle of impedance matching between load and PV module, which is necessary for maximum power transfer. This impedance matching is done by using a DC to DC converter. It step ups or step downs the source voltage at MPP depending on the output of controller.

The algorithm used in the controller is to track the maximum power point. Different Algorithms are existing and are being developed. Among the various conventional methods for MPPT, the most commonly used are Perturb \& Observe Method, Incremental conductance Method, Fractional Short Circuit Current Method, Fractional Open Circuit Voltage Method, Fuzzy Logic Control Method, etc., The primary algorithm implemented in the MPPTs is the $\mathrm{P} \& \mathrm{O}$ method which involves perturbing the point of operation and observing the power delivered by the PV array. Such a course of action leads to climbing of the hilllike P-V curve to ultimately reach the MPP \& oscillate around it until the $\mathrm{P}-\mathrm{V}$ curve changes due to the next change in atmospheric conditions. The major benefits of this technique include relatively simple and easy understand. In some papers, $\mathrm{P} \& \mathrm{O}$ is also referred as Hill climbing method because it uses the same concept in perturbing Maximum power point. In fact the only difference between them is the output control variable in which $\mathrm{P} \& \mathrm{O}$ produces the change from the reference voltage to the converter while Hill climbing produces the change from the duty cycle [1].

The two critical weaknesses of voltage P\&O is that, the system oscillates around the MPP which will cause loss of energy. Secondly, it will not be able track the maximum power point during fast changing of weather condition. A major challenge faced by this algorithm is the tendency of tracking in the wrong direction which is known as drift. These limitations are overcome in Incremental conductance MPPT algorithm. Incremental conductance method utilizes the fundamental concept of hill climbing, in which the slope of the PV array power curve is zero at the MPPT, positive at the left side and negative at the right side of the PV curve [1][2].

\section{PV SYSTEM}

The solar energy is popularly used to provide heat, light and electricity. One of the most important technologies is photovoltaic (PV) which converts the radiation directly to electricity by the photovoltaic effect [3]. The solar cells are mostly made of silicon (14-17\% of cell efficiency) or Gallium Indium Phosphide (30-35\% of cell efficiency) and are available in the form of arrays or panels [4]. This generated voltage is used for charging batteries which is further given to AC or DC loads depending on the load used as shown in Fig.1.
Block Diagram of Battery Charging System Using Solar Energy 
INTERNATIONAL JOURNAL OF INNOVATIVE RESEARCH IN ELECTRICAL, ELECTRONICS, INSTRUMENTATION AND CONTROL ENGINEERING Vol. 4, Issue 1, January 2016

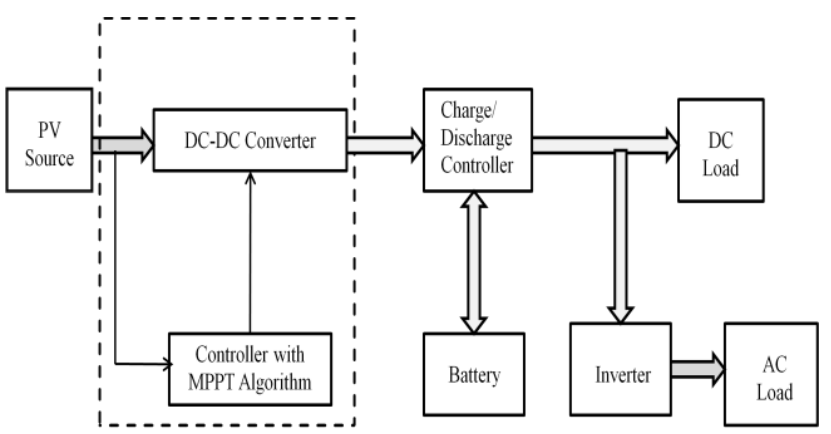

MPPT Mechanism

Fig. 1. Block diagram of Battery charging system

A detailed block diagram of the battery charging system is shown in Fig.1 which consists of

$>$ Photovoltaic $(\mathrm{PV})$ source

$>$ DC-DC converter

C Controller with MPPT algorithm

$>$ Charge or discharge controller

$>$ Battery with DC Load

$>$ Inverter with $\mathrm{AC}$ load

Description: The PV module converts the incident solar radiation into electrical power. For the better utilisation of the power generated Maximum Power Point Tracking is preferred [5]. The main block of this is the MPPT Mechanism. The maximum power point tracking mechanism makes use of an algorithm and an electronic circuitry [6]. The mechanism is based on the principle of impedance matching between load and PV module, which is necessary for maximum power transfer [7]. This impedance matching is done by using a DC to DC converter. It step ups or step downs the source voltage at MPP depending on the output of controller. The algorithm used in the controller is to track the maximum power point [8]. Different Algorithms are existing and are being developed.

\section{B. Incremental Conductance (Inc) Method}

Incremental conductance method utilizes the fundamental concept of hill climbing, in which the slope of the PV array power curve is zero at the MPPT[9], positive at the left side and negative at the right side of the curve as shown in the Fig. 2 [1][2].

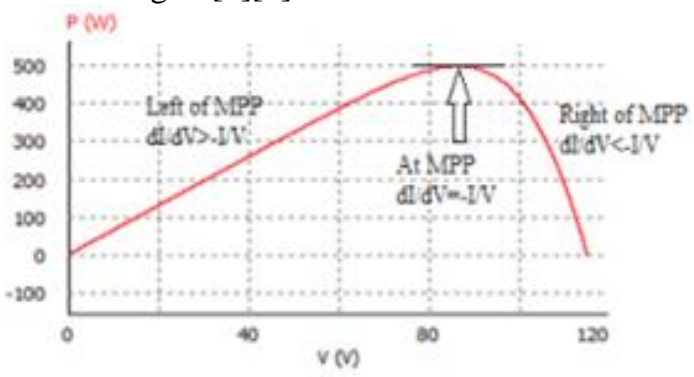

Fig. 2. Operating principle of $\mathrm{InC}$

At MPP, $v=$ vamp,$\frac{d p}{d v}=0 \Rightarrow \frac{d I}{d V}=-\frac{I}{V}$

Left of MPP, $v<v_{m p}, \frac{d P}{d V}>0 \Rightarrow \frac{d I}{d V}>-\frac{I}{V}$
Right of MPP, $v>v_{m p}, \frac{d P}{d V}<0 \Rightarrow \frac{d I}{d V}<-\frac{I}{V}$

Operation: It is based on the fact that the derivative of out power "P" for the voltage of the solar module becomes " 0 " at the maximum power point (MPP) [10]. The following equation using $\mathrm{P}=\mathrm{VI}$ relationship is calculated,

$$
\begin{aligned}
& \frac{d P}{d V}=\frac{d(\mathrm{VI})}{d V}=I \cdot \frac{d V}{d V}+v \cdot \frac{d I}{d V} \\
& \Rightarrow \frac{d P}{d V}=I+V \cdot \frac{d I}{d V}
\end{aligned}
$$

(5) When MPP is reached, the slope $\frac{d P}{d V}=0$,

then, $\frac{d I}{d V}=-\frac{I}{V}$

(6) i.e, Incremental conductance $=$ instantaneous conductance.

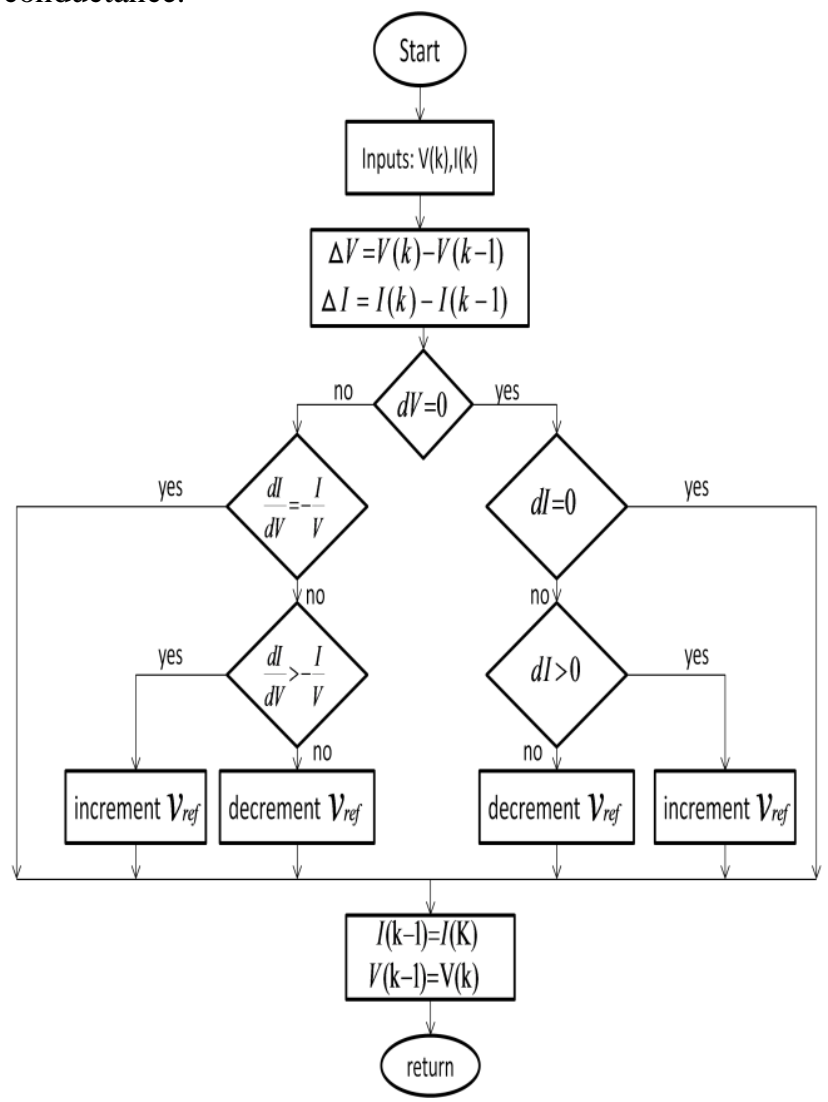

Fig. 3. Flow chart of InC

The MPP can be determined by comparing both the conductance $\&$ is attained when both the conductance are equal according to equation (6) [11]. The flowchart depicts the procedure to track the MPP by using reference voltage, $\&$ in theory, the MPP will maintain constant without oscillations until the current changes [12]. The change in current indicates the change in irradiation level. This method is therefore capable to capable to track the MPP during rapid variation of sun irradiation [13].

The main advantage is that it can be used to determine the maximum power point without oscillating around this value and also eliminates the steady state error and drift 
INTERNATIONAL JOURNAL OF INNOVATIVE RESEARCH IN ELECTRICAL, ELECTRONICS, INSTRUMENTATION AND CONTROL ENGINEERING Vol. 4, Issue 1, January 2016

[14]. The main drawback of this algorithm is that it is Expensive and complex system. This complex computation leads to slow convergence speed.

\section{SIMULATION}

Simulation is the process of using modern computer software and hardware to analyse the potential outcome of a given situation, based on known factors and introduction of one or more variables that have the ability to influence the outcome of any given situation. The power of simulation is that even for easily solvable linear systems a uniform model execution technique can be used to solve a large variety of systems without resorting to a "bag of tricks" where one must choose special-purpose and sometimes arcane solution methods to avoid simulation.

\section{A. Simulation of PV Cell}

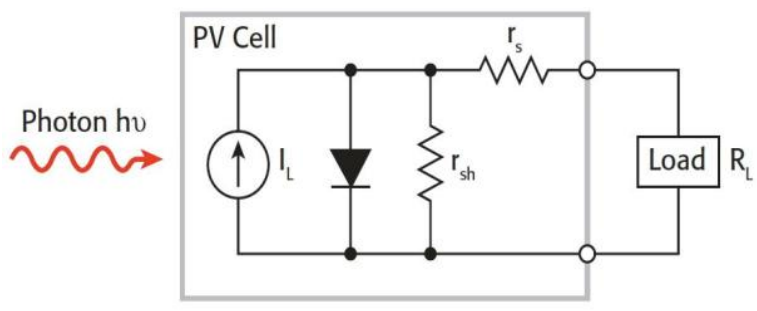

Fig. 4. Equivalent circuit of PV cell

The equations representing the operation of equivalent circuit of PV cell in Fig. 4 are given below:

$$
\begin{aligned}
& \left.I=\left[N_{p} I_{s c}-N_{p} I_{0}\left(e^{\left(\frac{V}{N_{s}}+I R_{s} T\right.}\right)-1\right)-\frac{V / N_{s}}{R_{s h} T}\right] \\
& R_{s} T=\frac{N_{s}}{N_{p}} R_{s} \\
& R_{s h} T=\frac{N_{p}}{N_{s}} R_{s h} \\
& I_{s c}=\frac{G}{1000}\left[I_{s c r}+K_{i}\left(T_{c}-T_{r}\right)\right] \\
& V_{o c}=N_{s} \ln \left(\frac{I_{s c}}{I_{o}}+1\right)\left(\frac{A K T_{c}}{q}\right)
\end{aligned}
$$

TABLE I : SPECIFICATIONS DATA OF PV PANEL XH250P (72) SOLAR PANEL [15]

\begin{tabular}{|l|l|l|}
\hline Type & Unit & \\
\hline Model & & XH250P(72) \\
\hline Irradiance(G) & $\mathrm{W} / \mathrm{m}^{\wedge} 2$ & 1000 \\
\hline No. of series cells (Ns) & Number & 72 \\
\hline No. of parallel cells(Np) & Number & 1 \\
\hline Max-Power (Pmax) & Watts & 250 \\
\hline Max-Voltage(Vm) & Volts & 34.4 \\
\hline Max-Current(Im) & Amp & 7.27 \\
\hline Open circuit Voltage (Voc) & Volts & 42.6 \\
\hline Short circuit Current (Isc) & Amp & 7.82 \\
\hline
\end{tabular}

\begin{tabular}{|l|l|l|}
\hline Cell temperature (Tc) & Kelvin & 298 \\
\hline Reference temperature (Tr) & Kelvin & 273 \\
\hline Series resistance (Rs) & Ohms & $5 \mathrm{E}-7$ \\
\hline Shunt resistance (Rsh) & Ohms & $5^{*} 10^{\wedge}(-7)$ \\
\hline $\begin{array}{l}\text { Reverse saturation current } \\
\text { at standard condition(Io) }\end{array}$ & Amp & $1.6234^{*} 10^{\wedge}(-7)$ \\
\hline
\end{tabular}

The PV cell with above specifications is simulated in LabVIEW. The simulated PV cell is shown in Fig 5:

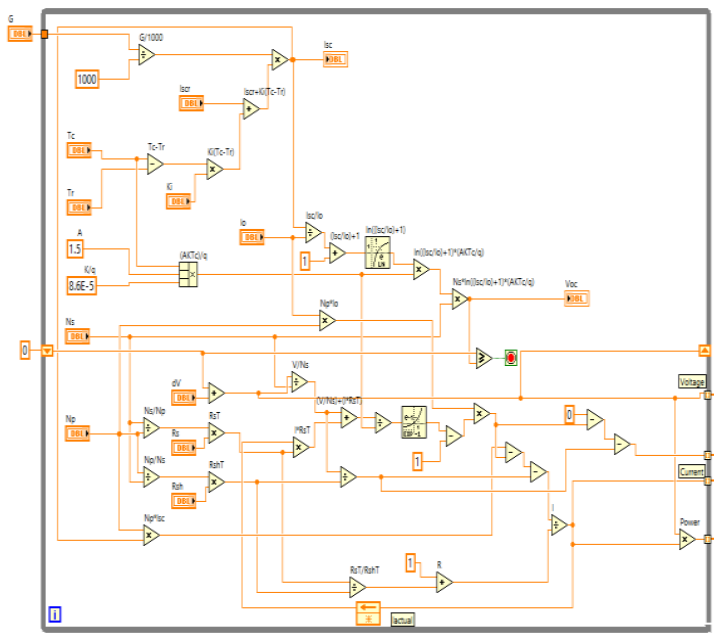

Fig. 5. PV panel simulation

B. Simulation of Incremental Conductance Algorithm

The simulation of MPP tracking of PV panel using Incremental Conductance Algorithm is shown in the Figure 6. This InC Algorithm is simulated by using the flow chart mentioned in the above. Case structure is used for implementing the conditional operations in the flow chart.

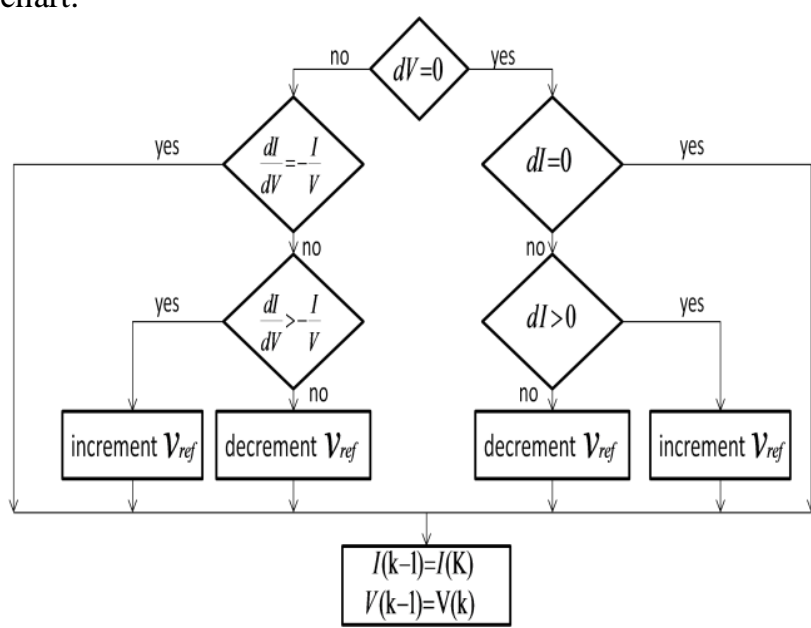

FIG. 5 FLOWCHART OF INC ALGORITHM

The flowchart of above algorithm is performed in LabVIEW as shown in Figures 6 (a-f).
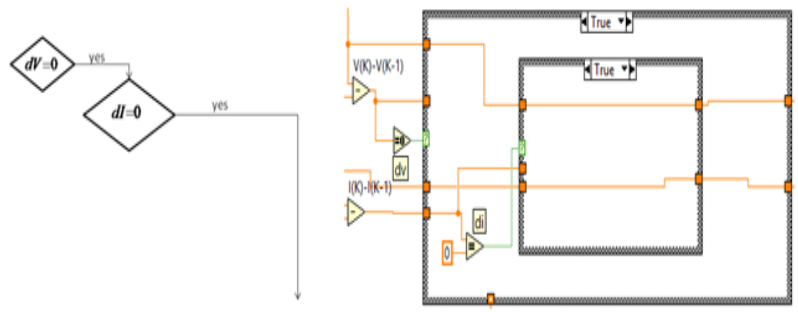

Fig. 6(a) 
INTERNATIONAL JOURNAL OF INNOVATIVE RESEARCH IN ELECTRICAL, ELECTRONICS, INSTRUMENTATION AND CONTROL ENGINEERING Vol. 4, Issue 1, January 2016

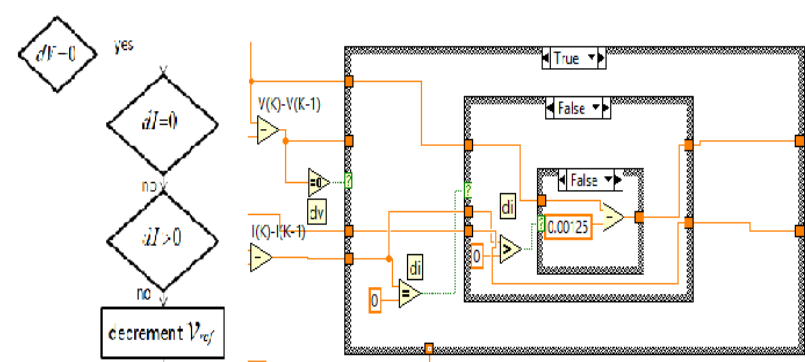

Fig. 6(b)
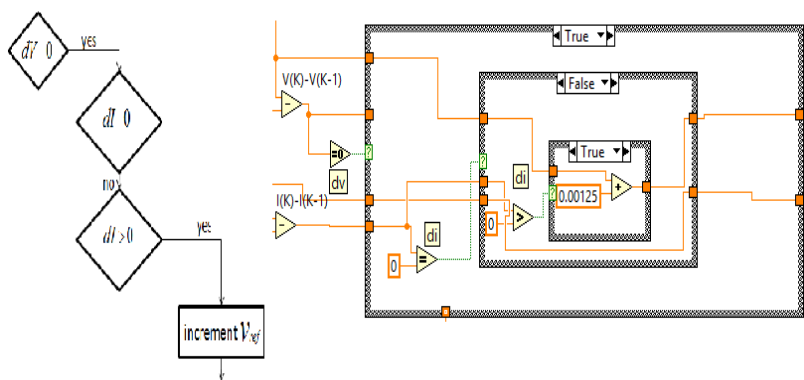

Fig. 6(c)

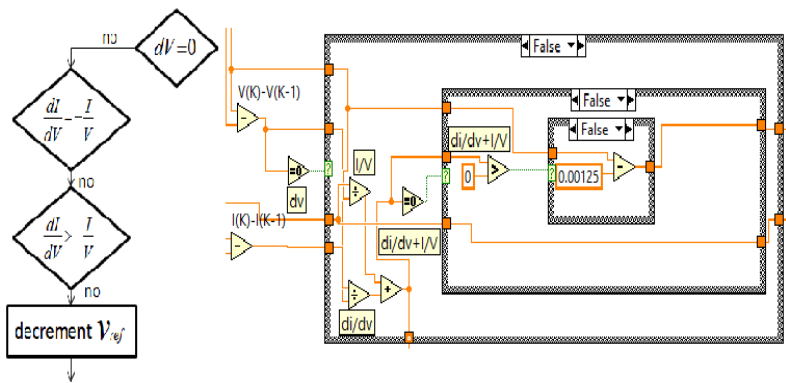

Fig. 6(d)

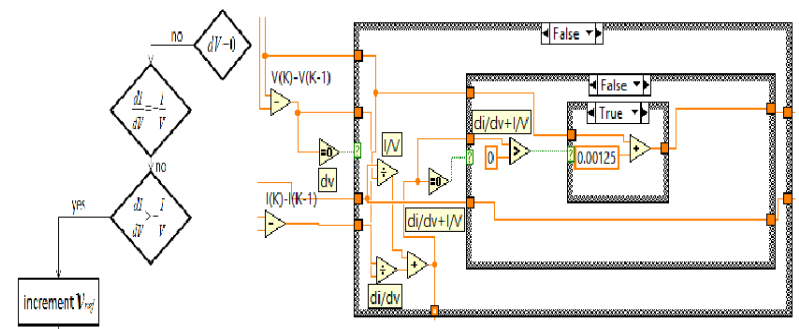

Fig. 6(e)

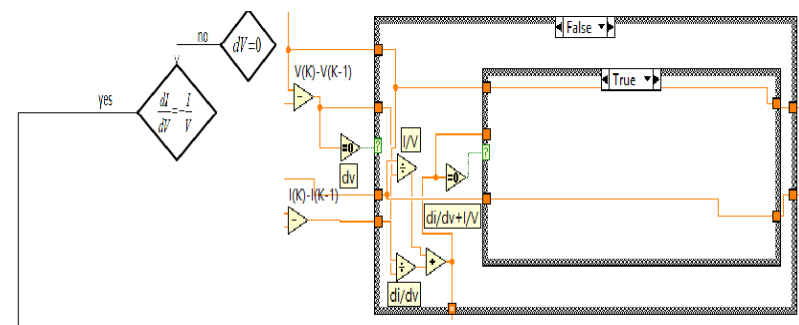

Fig. 6(f)

\section{Simulation Results}

The MPP tracking of PV Panel Characteristics by InC algorithm at an irradiance value $\left(\mathrm{G}=1000 \mathrm{w} / \mathrm{m}^{2}\right)$ is shown in Fig. 7.

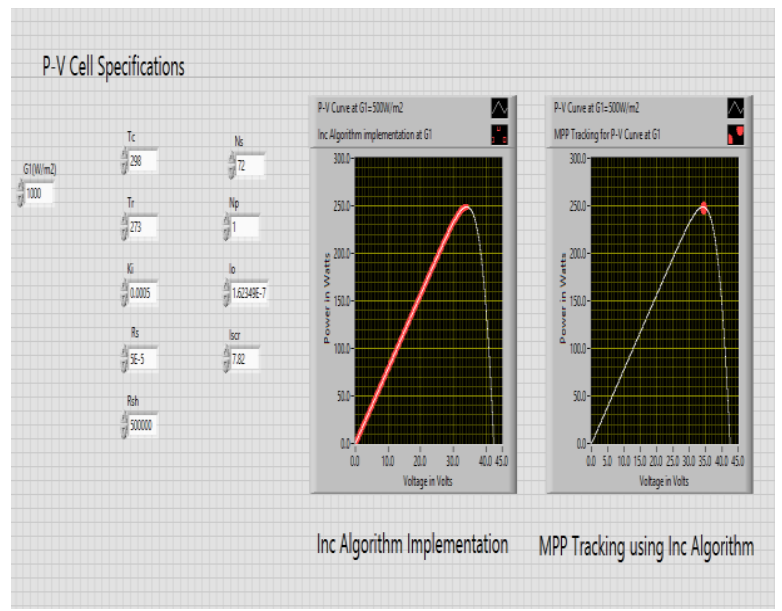

Fig. 7. PV characteristics of InC algorithm

\section{Observation}

For irradiance value of $1000 \mathrm{w} / \mathrm{m}^{2}$, a maximum power of 248.90 watts at 34.14 volts.

TABLE II: TABLE DISPLAYING THE VALUES OF POWER AND VOLTAGE OF PV PANEL WITH INC ALGORITHM AT IRRADIANCE $\mathrm{G}=1000 \mathrm{w} / \mathrm{M}^{2}$ CONDITIONS

\begin{tabular}{|c|c|c|}
\hline $\begin{array}{c}\text { Voltage in } \\
\text { Volts - P-V } \\
\text { Curve at } \\
\text { G=1000W/m } / \mathbf{m}^{2} \\
\end{array}$ & $\begin{array}{l}\text { Power in } \\
\text { Watts }\end{array}$ & $\begin{array}{l}\text { Voltage } \\
\text { in Volts }\end{array}$ \\
\hline 1 & 7.8 & 1 \\
\hline 2 & 15.7 & 2 \\
\hline 4 & 31.3 & 4 \\
\hline 5 & 39.2 & 5 \\
\hline 6 & 47 & 6 \\
\hline 7 & 54.8 & 7 \\
\hline 8 & 62.7 & 8 \\
\hline 10 & 78.3 & 10 \\
\hline 11 & 86.2 & 11 \\
\hline 12 & 94 & 12 \\
\hline 13 & 101.8 & 13 \\
\hline 14 & 109.7 & 14 \\
\hline 15 & 117.5 & 15 \\
\hline 16 & 125.3 & 16 \\
\hline 22 & 172.2 & 22 \\
\hline 23 & 180 & 23 \\
\hline 24 & 187.8 & 24 \\
\hline 25 & 195.5 & 25 \\
\hline 26 & 203.1 & 26 \\
\hline 27 & 210.7 & 27 \\
\hline 28 & 218.1 & 28 \\
\hline 29 & 225.2 & 29 \\
\hline 30 & 231.9 & 30 \\
\hline 31 & 238.1 & 31 \\
\hline 32 & 243.2 & 32 \\
\hline 33 & 247 & 33 \\
\hline 34 & 248.6 & 34 \\
\hline 35 & 247 & 35 \\
\hline
\end{tabular}

The above simulation results show that the $\mathrm{InC}$ algorithm tracks the MPP at different irradiance levels effectively.

The Incremental Conductance method has less performance during clear sky and cloudy sky conditions but has better performance in partly cloudy conditions. 
Simulation Results: The P-V Characteristics with InC algorithm at variable irradiance values is shown in Fig. 8. It is seen that both the MPP techniques are only tracking the local MPP but not the Global MPP.

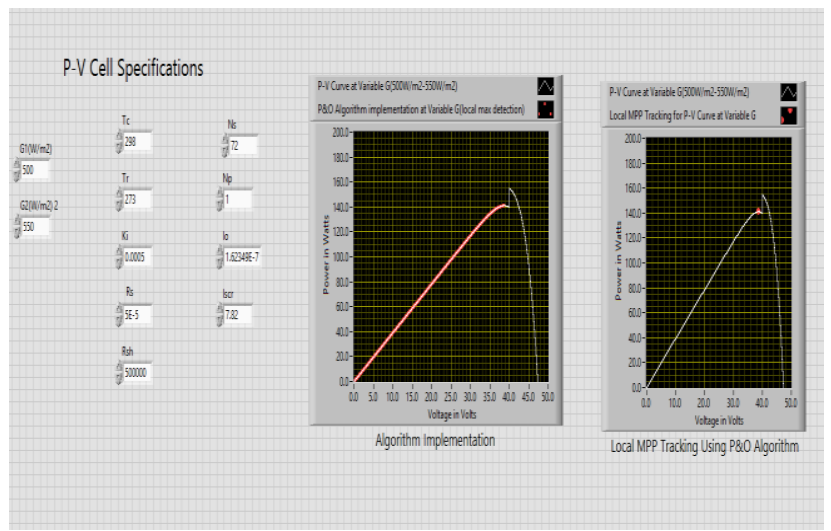

Fig. 8. PV characteristics for a InC algorithm

\section{CONCLUSION}

In this paper, the MPPT algorithms i.e., InC techniques for a PV system are simulated at different irradiance conditions using LabVIEW. With the simulation results, the performance of the algorithm for MPP tracking of PV system has been observed. The $\mathrm{P} \& \mathrm{O}$ is simple but has a limitation of drift which is reduced in $\mathrm{InC}$ method. It has also been observed that InC method cannot track the global MPP but only tracks the local MPP under partial shaded conditions.

\section{REFERENCES}

[1] AwangJusoh, ToleSutikno, TanKazGuan and SaadMekhilef, "A Review on Favorable Maximum Power Point Tracking Systems in Solar Energy Applications" Telkomnika,Vol.12,No.1,March 2014,pp.6-22.

[2] A.K.Mukerjee, Nivedita Thakur, "Photovoltaic Systems Analysis \& Design",211,PHI Learning Private Limited,Delhi-110091.

[3] Bruce Cross, PV System monitoring, Practical Handbook of Photovoltaics Fundementals and Applications, Edited by Tom Markvart and Luis Castaner, Elsevier, 2006 (pg 539)

[4] Joung-Hu Park, Jun-Youn Ahn, Bo-Hyung Cho and Gwon-Jong $\mathrm{Yu}$ " DualModule-Based Maximum Power Point Tracking Control of Photovoltaic System," IEEE Trans., Vol. 53,no.4, pp .1036$1047, .2009$

[5] T. Esram, P.L. Chapman. Comparison of Photovoltaic Array Maximum Power Point Tracking Techniques. IEEE Transactions on Energy Conversion. 2007; 22(2): 439-449.

[6] Batteries and Charge Control in Stand-Alone Photovoltaic Systems Fundamentals and Application-Prepared by:James P. Dunlop, P.E.Florida Solar Energy Center1679 Clearlake RoadCocoa, FL 32922-5703

[7] Marzuq Rahman, et al; "Design of a Charge Controller Circuit for multilevel Solar Panels for Solar Home System," 2012.

[8] Mohamed Azab, "A New Maximum Power Point Tracking for Photovoltaic Systems," World Academy of Science, Engineering and Technology, 442008.

[9] World Academy of Science, Engineering and Technology 442008 A New Maximum Power Point Tracking for Photovoltaic SystemsMohammed Azeb

[10] National Instruments (www.ni.com)

[11] Dr. J. Abdul Jaleel, Nazar. A, Omega A R.Simulation on Maximum Power Point Tracking of the Photovoltaic Module using LabVIEW, International Journal of Advanced Research in Electrical, Electronics and Instrumentation Engineering Vol. 1, Issue 3, September 2012.

[12] T. Esram, P.L. Chapman. Comparison of Photovoltaic Array Maximum Power Point Tracking Techniques. IEEE Transactions on Energy Conversion. 2007; 22(2): 439-449.
13] M.S.ait Cheikh*,C.Larbes*,G.F.Tchoketch Kebir and A.Zerguerras, "Maximum Power Point tracking using a fuzzy logic control scheme", Revue des Energies Renouvelables Vol.10 N³(2007) 387 395,(recu le 20 April 2007-accepte le 25 September 2007).

[14] N. Pongratananukul. Analysis and Simulation Tools for Solar Array Power Systems [PHD's Thesis].University of Central Florida, Department of Electrical and Computer Engineering. 2005.

[15] D.S. Morales. Maximum Power Point Tracking Algorithms for Photovoltaic Applications [Master's Thesis]. Aalto University, Faculty of Electronics, Communications and Automation. 2010.

\section{BIOGRAPHIES}

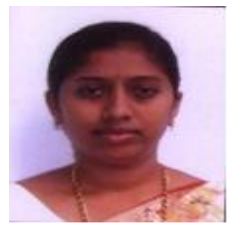

Kodali Vijaya Lakshmi was born in Visakhapatnam, India, in 1982. She received the $B . T e c h$ degree in Instrumentation Technology from VR Siddhartha Engineering College, Vijayawada, India, in 2003, and the M.Tech. degree in Industrial Process Instrumentation from the Andhra University, Visakhapatnam, India, in 2006. In 2006, she joined the Department of Electronics and Instrumentation Engineering, VR Siddhartha Engineering College, Vijayawada, as a Lecturer and currently she is an Assistant Professor. She has 9 years of teaching experience and a number of technical publications in peer reviewed journals. Her current research interests include process control, process modelling and simulation, neural networks and optimization techniques. Mrs. Kodali is a Life Member of the Instrument Society of India (ISOI) and the Biomedical Engineering Society of India (BMESI).

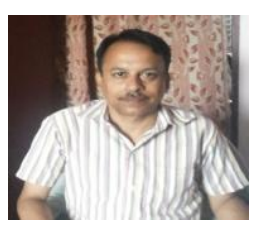

Paruchuri Srinivas was born in Andhra pradesh, India, in 1970. He received the M.Tech. degree in Electronic Instrumentation from NIT Warangal, India, in 1992. In 1993, he joined the Department of Electrical and Electronics Engineering, VR Siddhartha Engineering College, Vijayawada, as a Lecturer and currently he is an Associate Professor in Electronics \& Instrumentation Engineering in the same college. He has 20 years of teaching experience and a number of technical publications in peer reviewed journals. His current research interests include control systems and optimization techniques. He is a Life Member of Indian Society technical Education(ISTE), the Instrument Society of India (ISOI) and the Biomedical Engineering Society of India (BMESI).

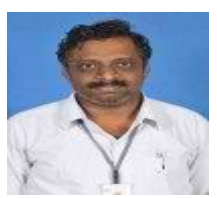

Ch.Ramesh was born in Andhra pradesh, India. He received the M.Tech. degree in Electronic Instrumentation from NIT Warangal, India, in 1992.At present he is working as a professor and head in Electronics \& Instrumentation Engineering department, Bapatla Engineering college, Bapatla . He has 18 years of teaching experience and a number of technical publications in peer reviewed journals. His current research interests include communications. and optimization techniques. 